\title{
How Covid-19 Impact on Technological Equipment
}

\author{
Kerimova N.K. \\ Azerbaijan State Economic University - UNEC, Baku, Azerbaijan \\ *Corresponding author. Email: nurlana_karimova@unec.edu.az
}

\begin{abstract}
In the article, the author focused on the global technology forum: The Covid-19 pandemic and quarantine will cost the world dearly: the corona crisis has already begun and is predicted to be the most devastating crisis of the century.

The 2019 coronavirus (COVID-19) pandemic is devastating and has enormous negative impacts on individuals, families, population groups, and communities around the world. Everyday life has undergone profound changes, countries are in a recession, and many of the traditional social, economic, and public health support systems that many people rely on during difficult times are under unprecedented pressure.

The demand for technological equipment has risen as the coronavirus has taken over the world. The world's population is aware of the processes occurring in the world in the field of technological equipment.

Keywords: covid-19, technology, corona crisis, Internet resource, technological equipment

\section{INTRODUCTION}

The coronavirus (COVID-19) pandemic is affecting families, communities, and businesses around the world. The experts in the field of technology should understand how they can help deal with the challenges that businesses have during COVID-19.The successful application of technology for teleworking and remote service delivery can be very useful.

"Human history is, in many ways, the history of

closure - even temporary - of offline stores of such giants as Apple and Tesla have affected the profits of tech corporations.

But we should not forget about the flip side of the coin. The coronavirus not only accelerated the digital transformation of enterprises - many had to move almost all processes online - but also forced scientists to find new ways to use high technology for their purposes. All means are used to fight the coronavirus, including artificial intelligence and big data.
\end{abstract} technology. For this reason, the story of the next 50 years will depend on what the wise men in Bangalore or the intellectuals in New York discover. Or rather, the main directions of our development will determine how society will benefit from these scientific and technological discoveries. However, other factors will also play a role, such as changes in nature or the emergence of ideologies that can challenge global capitalism. However, it is technical progress that will continue to be the main engine of all innovations. Richard Watson, the author of «The Story of the Next 50 Years», believes that technological innovation can play both positive and negative roles as a driving force in society. The situation may even reach a point where a person is rebelling against technology.

Today the world is on the brink of new global changes. The innovations that have entered our lives with the advent of the Fourth Industrial Revolution (Industry 4.0) - the wider use of information and telecommunication technologies, the use of the Internet by about $60 \%$ of the world's population (this figure has increased against the backdrop of the COVID-19 coronavirus pandemic), robotization and artificial intelligence technologies, The Internet of Things (IoT - Internet of Things), big data (Big Data) and digitalization resulting from all of the above, opens up new opportunities for us. These opportunities are revealing themselves now more than ever.

The tech industry has been hit by the coronavirus. The suspension of production, disruption in supply chains, the

\section{RESEARCH METHODOLOGY}

In connection with the coronavirus infection that began in China early this year and the announcement of the virus (COVID-19) as a pandemic by the World Health Organization on March 11, millions of people in their homes and offices began to use digital platforms more actively. The worldwide coronavirus pandemic resembles the "Black Swan" phenomenon (a term used by the American economist and writer Nassim Talebi in his book "Black Swan. Under the Sign of Unpredictability" meaning a global phenomenon that is difficult to predict and has an impressive impact). This time, the emergence of a new type of coronavirus epidemic caused a debate in the world of the economy's digitalization and various fields of activity, and the acceleration of the transition to the digital economy.

The coronavirus is giving impetus to the use of new generation technologies, bringing digital technologies to the foreground.

At the moment, the Black Swan phenomenon, in addition to opening the way to changes in the economy at the global level, can also change our behavior - change both people and organizations. Against the backdrop of the pandemic, heads of government are rejecting international 
face-to-face meetings, preferring conferences in Skype, Zoom, and other similar programs; business, education, and other various fields are moving to the online platforms. Significant cost savings have come from telecommuting and video conferencing, a variety of connectivity services, and millions of people working outside the office. Experts believe that in the fight against the pandemic, fast delivery without people or contact fully demonstrates its benefits. Service robots, self-service stores without salespeople, etc. - are shaping a new direction and helping to reduce the risk of infection. The spread of infection in the world, isolated many cities in America, Europe, and Asia and seriously influenced the development of digital technologies in the economy. Fearing a virus infection, people and companies now prefer online trading to its offline counterpart, which increases the share of e-commerce.

The current situation leads to a great demand for online applications, digital technologies, and this, in turn, makes it necessary for the existence and construction of sustainable infrastructure in the countries of the world. So, thanks to the transition of millions of people to a home mode of work, the demand for connection services is growing rapidly, the volume of content transmitted over the Internet is increasing, which makes it necessary to develop infrastructure.

\section{REMOTE WORK}

Practical aspects of working from home. Have you ever thought about the fact that not all employees have a) laptops and b) internet connection? Have you assessed who needs to work from home, and which resources they have at home?

Connectivity. Have you considered the possibility of providing mobile hotspots for those who do not have access to the Internet, if such hotspots can be obtained?

Network power. Have you appreciated the ability to increase your bandwidth to support more employees remotely?

Virtual desktop. If you don't have enough laptops for your employees, are you considering scaling virtual desktops so that more employees can work remotely?

Collaboration tools. Are you planning to increase the load on collaboration tools? Changing demand for IT resources?

Changing customer behavior. Self-isolation may lead to customers switching to digital channels. Have you analyzed how you will provide support to customers who first turn to such channels? Do you have the proper IT infrastructure and sufficient resources for technical and customer support?

It is very important to update the performance forecast. Have you evaluated how the behavior of your users and customers will change and how this will affect the use of your IT services? Your forecasting and capacity planning based on normal usage parameters may become irrelevant.

\section{RESEARCH RESULTS}

Air disinfectants: catch and neutralize the virus.

The list of the main helpers in the fight against the virus includes air disinfectants. These are portable and stationary models, in which various protection mechanisms are used: ultraviolet radiation, bacterial mechanical filters, exposure to aerosols of disinfectants and ozone, etc. The production of such devices now increases at Rostec enterprises.

For example, POZIS is ready to supply its range of compact recirculators. Such a device is called a "wallmounted bactericidal recirculator-irradiator ". It is designed to quartz air and surfaces using ultraviolet rays, which kill viruses and bacteria. The degree of disinfection is impressive $-99.9 \%$.

Unlike quartz lamps of the old type, air disinfection with new POZIS recirculators is carried out by the method of ultraviolet irradiation, which is safe for human health, in a closed chamber of the device. That is, the radiation spreads only to the inner part of the recirculator body and does not contact with a person. Thus, it is possible to conduct air disinfection in the presence of people. Among the novelties in air purification technologies are photocatalytic filters. They can cope with $99 \%$ of bacteria and viruses, and they can also become an effective way to combat the ill-fated COVID-2019. The main advantage of such filters is that microorganisms do not accumulate in them - they break down into safe molecules of water and carbon dioxide. In Russia, such air cleaners are produced at the CRET (concern Radio-Electronic Technologies) enterprise. The concern has already announced that it is ready for mass deliveries of air purification systems to medical institutions, train stations, airports, as well as to industrial and other facilities to protect against epidemics.

But the designers of the Concern did not stop there - they were the only ones in the world who managed to integrate photocatalytic filters into personal protective equipment. The Ramen instrument-making Plant (RIMP), which is part of CRET, has already produced an experimental batch of innovative antimicrobial respirator masks with photocatalysis technology. Such a respirator allows you to protect a person not only from dangerous viruses but is also effective against all types of microorganisms, including tubercle bacillus, as well as mold and fungal spores, bacteria, and any volatile organic compounds.

At the moment, authorities, private companies, and scientists are trying to find new ways to combat the virus. In China, police have used drones to track people not wearing masks in endangered areas, and Internet giants (Google, Facebook, Amazon, etc.) have launched a campaign to combat fake information related to the virus. The Canadian company "BlueDot" collects information from all over the world about cases of new infections, and using artificial intelligence is trying to predict the presence of infected in new territories in China and other countries of the world. American startup "AIME" (Artificial Intelligence in Medical Epidemiology - Medical Epidemiological Artificial Intelligence) has been using 
artificial intelligence capabilities since 2015 to analyze epidemics and predict them.

China's real-time fight against coronavirus has shown the world the power of modern technologies and superApps (special mobile applications that combine several services). At the end of December 2019, the cases of infection that broke out in China began to decrease by February, thanks to the mobilization of the country and the use of all possible means in the fight against the virus. The use of artificial intelligence applications by large Chinese companies such as Baidu, Alibaba, Alipay, and others has led to significant effects. More than $50 \%$ of inquiries entering the medical system were transferred to the online format, as carriers of the virus could transmit it during a visit to the doctor. For this, a connection to a high-speed $5 \mathrm{G}$ network was created, and the widespread use of the telemedicine system began. At the same time, medical applications were made available to connect patients with doctors, pharmacies, as well as applications that provide useful tips to combat the virus. What is happening demonstrates that mitigation of the damage caused by epidemics is becoming possible thanks to information technology and the Internet - digitalization has changed the approach of humanity to diagnosing and monitoring many diseases.

\section{THE DISCUSSION OF THE RESULTS}

The main goal here is to introduce digital technologies into all spheres of public life, from various sectors of the economy to urban infrastructure. This process, in turn, covers five areas: education, infrastructure, information security, regulation, scientific and technological development.

Education - the key point here is to improve the system to provide the digital economy with qualified personnel. The population must learn some digital skills. At the moment, as a result of the pandemic, we see the need to switch the educational system to online mode.

Infrastructure - infrastructure development is a priority since it is necessary to create a single system that could store and process data. Building a digital economy is closely linked precisely to sustainable infrastructure. Because modern technological infrastructure is the basis of digitalization and the digital economy.

Information Security - in connection with the increase in cases of information leakage in the world, the development of cybersecurity will protect user data, both from internal and external factors. For this, it is necessary to increase the literacy of the population in the field of information security. At the same time, all hospitals, schools, universities, and residential areas in the country must have Internet access.

Scientific and technological development - supporting research in the digital economy ensures the development of end-to-end technologies. These technologies include most of all: artificial intelligence, augmented and virtual reality technologies, big data, quantum technologies, robotics, digital medicine, and blockchain.
The development of the digital economy requires the use of new technologies and the creation of a regulated environment that does not interfere with its functioning.

Sustainable infrastructure is the foundation of digitalization and the digital economy.

\section{CONCLUSION}

ALV apparatuses: Last Chance to Save

Doctors around the world are talking about a shortage of ALV machines, which are required to save the lives of patients with severe pneumonia caused by the coronavirus. In turn, the largest manufacturers of ALV machines are trying to increase the production of devices to meet the growing demand. Even the founder of the aerospace company SpaceX and the head of Tesla, Elon Musk, announced their willingness to start producing artificial lung ventilation devices.

In any big country, there are at least two or three companies producing mechanical ventilation devices. There are also several such manufacturers in Russia, including CRET and «Shvabe». The Corporation's product line includes universal devices that are suitable for both adults and children, as well as devices for home use and mobile transport options for ambulances and air ambulances.

For example, CRET has been successfully producing the Aventa-M ALV machine for children and adults for several years, the feature of this device is the use of a turbine drive in the apparatus, which increases the productivity and reliability of the machine. The display shows all digital parameters and respiratory graphics, including real-time monitoring. "Aventa-M" has functionality comparable to more expensive ventilators from leading European manufacturers. This is the opportunity to transfer data using Wi-Fi to the nosocomial and interhospital network, auto-control of intelligent functions, and analytical programs for transferring patients to spontaneous breathing.

The multifunctional device for inhalation anesthesia MAIA-01 "Shvabe" is today the only domestic device that combines the functions of artificial lung ventilation, anesthesia, and complex monitoring of the respiratory mixture. This type of equipment is produced in our country for the first time. According to its characteristics, it can compete with the most famous foreign analogues, and it is much cheaper.

«Shvabe» and CRET are now increasing the production of ALV machines and are ready for new supplies. Nevertheless, according to doctors, if the development of the epidemic in Russia follows the global scenario, domestic hospitals may also face a shortage of mechanical ventilation devices. In Italy, where the number of people infected with COVID-19 has already exceeded 97 thousand people, and more than 10 thousand have died from complications of the disease, this is already a sad reality. Here and in other countries most affected by the pandemic, an acute shortage of ALV devices is forcing doctors to go to extreme measures - to connect up to four 
patients to one machine. In particularly difficult situations, many clinics have no other alternative.

The «Shvabe» holding recently announced that they have created a system that eliminates the risk of cross infection through the use of bactericidal filters with high efficiency both at the entrance to the apparatus and for each patient. At the same time, the novelty is compatible with any domestic and foreign ALV machines. "Thanks to the teamwork of the FMBA of Russia, the Rostec State Corporation and the Shvabe holding, we have managed to create experimental devices that allow us to ventilate from two to four patients without the risk of crosscontamination," said Veronika Skvortsova, head of the Federal Biomedical Agency of Russia.

The product has already passed all the necessary tests, and the holding is ready to launch its serial production.

As a result of the technological equipment's development, many negative events in the world can be prevented. Scientists around the world are currently trying to return the camel to its pre-coronavirus state by discovering new technological equipment.

\section{REFERENCES}

[1] D. Guellec, B. Van Pottelsberghe De La Potterie, From R\&D to Productivity Growth: Do The Nstitutional Settings and the Source of Funds of R\&D Matter? Oxford Bulletin of Econ. and Stat. 66(3) (2004) 353378.

[2] C. I. Jones, J. C. Williams, Too Much of a Good Thing? The Economics of Investment in R\&D, J. of Econ. Growth. 5 (1) (2000) 65-85.

[3] Abdul ve Syed Mahmud Jalil, Environment Kuznets curve for $\mathrm{CO} 2$ emissions: A cointegration analysis for China, Energy Policy 37 (2009) 5167-5172.

[4] R. M. Alguliev, R. M. Aliguliyev, A. M. Bagirov, Global optimization in the summarization of text documents, Aut. Control and Comp.Sci. 39 (2005) 4247.

[5] M. Verbic, B. Majcen, C. Mitja, O. Ivanova, R\&D and Economic Growth in Slovenia: A Dynamic General Equilibrium Approach with Endogenous Growth, Panoeconomicus. 1 (2011) 67-89

[6] C. R. Nelson, C.R. Plosser, Trends and Random Walks in Macroeconmic Time Series, J. of Monetary Econ. 10(2) (1982) 139-162. http://doi.org/10.1016/0304-3932(82)90012-5

[7] P. C. B. Phillips, P. Perron, Testing for a Unit Root in Time Series Regression, Biometrika 75(2) (1988) 335-346.
[8] A.J. Samimi, S.M. Alerasoul, R\&D and Economic Growth: New Evidence from Some Developing Countries, Australian J. of Basic and Applied Sci. 3(4) (2009) 3464-3469.

[9] A.J. Samimi, R.B. Ledary, ICT and Economic Growth: New Evidence from Some Developing Countries Australian J. of Basic and Applied Sci. 4(8) (2010) 3086-3091.

[10] M. Zachariadis, R\&D-induced Growth in the OECD? Rev. of Dev. Econ. Vol. 8 (3) (2004) 423-439. 